\title{
THE INFLUENCE OF SPEED, AGILITY, COORDINATION OF FOOT, BALANCE AND MOTIVATION ON SKILL OF PLAYING FOOTBALL
}

\author{
Ahmad Adil ${ }^{1}$, James Tangkudung ${ }^{2}$, Achmad Sofyan Hanif ${ }^{3}$ \\ State University of Jakarta ${ }^{1}$ \\ State University of Jakarta ${ }^{2}$ \\ State University of Jakarta ${ }^{3}$ \\ ahmad.adi1342@yahoo.co.id ${ }^{1}$ \\ jamestangkudung@unj.ac.id ${ }^{2}$
}

\begin{abstract}
This research uses survey method to see the influence between variables. Technique of data analysis using path analysis (path analysis). Path analysis technique is used to test the direct and indirect influence on speed, agility, coordination, balance and motivation to the playing skill of soccer student of Faculty of Sport Science Makassar public university. Technique of path analysis with SPSS program version 20.00 at significance level $\alpha=0.05$. The results of this study are as follows: (1) There is a positive influence of 0.612 between the speed of soccer playing skills and contributing $37.4 \%$ (2) There is a positive influence of 0.687 between agility to the skills of playing football and contribute $47.1 \%$ (3) There is a positive influence of 0.862 between eye-foot coordination of soccer playing skills and contributes $74.3 \%$ (4) There is a positive influence of 0.636 between the balance of soccer playing skills and contributes $40.4 \%$ (5) positive is 0.816 between motivation to soccer playing skill and contribute 66,6\% (6) There is positive influence equal to 0,531 between speed to motivation and contribute equal to $28,2 \%$ (7) There is positive influence equal to 0,621 between agility to motivation and contribute equal to $38.6 \%$ (8) There is a positive influence of 0.743 anta (9) There is a positive influence of 0,564 between the balance of motivation and contribution of $31.8 \%$ (10) There is a positive influence of 0.824 between the speed of the skills of playing football through motivation and contributing $66.8 \%$ (11) There is a positive influence of 0.879 between agility of soccer playing skills through motivation and contributing $67.3 \%$ (12) There is a positive influence of 1.344 between foottoe coordination of soccer playing skills through motivation and contributing $67,2 \%$ (13) There is a positive influence of 0.878 between the balance of soccer playing skills through motivation and contribute $67.0 \%$.
\end{abstract}

Keywords: Speed, agility, coordination, balance, motivation and the skills of playing football.

People believe that the role of sports provides a positive advantage for those involved in it, Football is a sport that is loved by all levels of society in Indonesia, both in cities and in villages. Even now football is also played by women. In promoting sports and sporting societies, football is one of the sports that is prioritized to be nurtured, so to improve and achieve the achievements it would be nice if ever since children have received a sport education and football in particular correctly, regularly and directed.

Football today is a sport that has popularized and popular up to all corners of Indonesia. Fans both male and female even up to the elderly people. This sport develops into a professional sport that is enough to guarantee the future of players.

Given the pleasure and love of the community to football, it is natural that the football coach is required to continue to fix themselves with knowledge and seek experience for the advancement of football both in club and in the world of education.

Students of the Faculty of Sport Science at Makassar State University have often participated in various competitions both at the regional and national levels, but the results have not been very satisfactory or rarely champions in every tournament that followed. But every national championship 
between students Football Club players Faculty of Sport Sciences Makassar State University always take part or contributor most players of all students in South Sulawesi.

In a soccer game it takes soccer playing techniques like dribbling, passing, stopping, throw in, heading, tricks and turns, shooting )

Even to train this approach technique is not wrong. But the problem in playing football is how players are able to apply and develop soccer playing techniques such as herding, passing and kicking appropriately in accordance with play situations and supported by optimal physical abilities such as speed, agility, coordination and balance and supported by high psychological factors such as motivation.

Basic techniques that must be mastered athletes in order to play the ball well is herding, passing and kicking. The technique of herding, passing and kicking is done continuously according to the game in each round. Thus, the technique of herding, passing and kicking good and fast is necessary, in order to be able to perform attacks and defenses in high tempo without experiencing significant difficulties. The dominance of the explosive motion is very visible when an athlete performs an attack in an effort to gain points or numbers, therefore the role of dribbling (dribbling) is fast, precise, and optimal in this case is very supportive.

The skill of playing the ball should be supported with ball control, control, deceptive ability, ability to change speed. If not supported by these factors then the skill cannot be done quickly so that the ball easily taken by opponent. Exercise regularly and structured or preprogrammed using the foot parts It is better to improve the playing of the ball.

According to Matteo Zago, Massimo Giuriola and Chiarella Sforza (2016: 710) stated that: Soccer performance is multifactorial and requires a range of physical qualities, including speed, endurance, agility, coordination, strength, balance, as well as perceptual and cognitive skills. Further According to Terry (2007: 2) skill is the consistent production of goal-oriented movements, which are studied and specific to the task.

Dribbling according to Lukman (2009: 23) is to play the ball while running, which can be done with a straight or twisted direction. Meanwhile, according to Luxbacher Football dribblers have the same function with a basketball that allows to maintain the ball when running across an opponent or forward to open space.

Passing the ball by Calm (2008: 83) football game is a game that prioritizes short passes or cool terms passing the game hence, a player must master the technique of feeding or passing the ball right

Meanwhile, according to Juan Antonio Garcia (2017: 1172) states that In fact, they emphasize that the faster the ball goes, the less time the defenders and goalkeeper will have to block it

Tangkudung (2012: 71) states that speed is the ability to walk, run and move very quickly. Next Harsono speed (speed) is the ability to perform similar movements in a row in the shortest time, or the ability to travel a distance in the shortest possible time.

According to Anderson and Susan (2009: 40) states that "Agility is the ability to change directions rapidly when moving at a high rate of speed. Balance is the body's coordinated neuromuscular response to maintain a visual, tactile, or kinesthetic stimuli "

Atmojo (2010: 59) says that "coordination is the ability to simultaneously perform various tasks of motion smoothly and accurately (appropriately)"

Meanwhile, according to Joaquin, Martin, Colado, Benaven, Martinez and Jorge (2017: 112) states that: "Agility and dynamic balance are crucial skills in prepubertal physical activity and sport participation, so the identification of efficient tests for their assessment is necessary. To evaluate the correlation between agility and dynamic balance in primary school children "

Meanwhile, according to Husdarta (2010: 31-32) in motivation learning activities can be interpreted psychological energy that is abstract. Its form can be observed in the form of manifestation 
of the behavior it displays. Motivation as a psychological process is a reflection of the power of interaction between cognition, experience and needs.

Based on the above explanation, the researcher conducted the research with the title "Effect of Speed, Agility, Eye-foot Coordination, Balance and Motivation of Soccer Playing Skills" The formulation of this research is: 1) Does the speed directly affect the skills of playing football.? 2) Does agility affect directly to soccer playing skills? 3) Does foot-eye coordination have an immediate effect on the skills of playing football.? 4) Does the balance directly affect the skills of playing football.? 5) Does the motivation have a direct effect on the skills of playing football.? 6) Does speed have direct effect on motivation? 7) Does agility affect directly to motivation.? 8) Does eye-foot coordination have direct effect on motivation? 9) Does the balance have direct effect on motivation? 10) Does speed have direct influence on the skills of playing football through motivation? 11) Does agility affect directly to the skills of playing football through motivation.? 12) Does eye-foot coordination have an immediate effect on the skills of playing football through motivation? 13) Does the balance directly affect the skills of playing football through motivation?

The objectives in this research are: 1) direct influence of speed to the skill of playing football. 2) The direct influence of agility on the skills of playing football. 3) Direct influence of foot-eye coordination of soccer playing skills. 4) The direct influence of balance on the skills of playing football. 5) The direct influence of motivation on the skills of playing football. 6) Direct influence of speed on motivation. 7) The direct influence of agility on motivation. 8) Direct influence of eye-foot coordination on motivation. 9) Direct influence of balance on motivation. 10) The direct influence of the speed on the skills of playing football through the motivation of Faculty of Sport Science of State University of Makassar students. 11) The direct influence of agility on the skills of playing football through motivation in Faculty of Sport Science of State University of Makassar students. 12) The direct influence of eye-foot coordination on soccer playing skills through motivation in Faculty of Sport Science of State University of Makassar students. 13) The direct influence of balance on the skills of playing football through the motivation of Faculty of Sport Science of State University of Makassar students.

\section{METHOD}

Method is a way of getting truth through observation. According to mukhtar research method is a logical, systematic, objective, to find the truth of science

According to Tangkudung (2016: 92) the path analysis model is used to analyze the influence relationship between variables with the aim to know the direct or indirect effect of a set of independent variables (exogenous) to the dependent variable (endogen). The variables studied consisted of six variables consisting of five exogenous variables and one endogenous variable. Exogenous variables consist of Speed (X1), Agility (X2), Eye-foot coordination (X3), Balance (X4) and Motivation (X5). Endogenous variable in this research is Skill of Playing Football (Y).

\section{Research Place}

This research was conducted in Faculty of Sport Science of State University of Makassar, implemented from January 2017 until June 2017. This research was conducted by applying to the Dean of Faculty of Sport Science of Makassar State University for the use of facilities and field and participation of Lecturers and Samples involved in the study of students Faculty of Sport Science State University of Makassar Department of Physical Education Health and Recreation who have passed soccer courses. With a total sample of 54 students. 


\section{Research design}

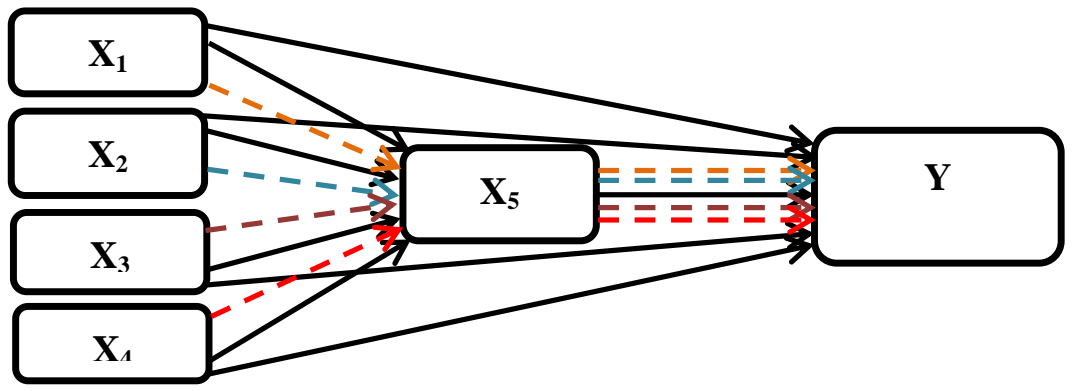

Information:

Direct Effect

Indirect Influence X1: Speed

X2: Agility

X3: Coordination Eyes-foot

X4: Balance

X5: Motivation

Y: Playing Skill of Soccer

Dribbling Ball The aspect measured in dribbling skill measurements is a dribbling test that scores the time the testee obtains in dribbling from start to finish plus the score of the dribbling instances that have been compiled by the researcher and validated by the team of test experts used is a dribbling skill test. Passing the ball The aspect measured in obtaining the data in this study is the score or the number of balls that go to the target that was successfully performed for 10 seconds recorded as the final score. Testees are given three occasions of execution, and the highest number of scores is used as research data. Validation of this research instrument is face validity, that is the concept of research instrument that has been standard. Kicking The Ball The aspect measured in the kicking skills of the ball using the test kicks the ball to the target plus the score of time the testee obtains in kicking the ball from start to finish, the kicking ball installs have been compiled by the researcher and have been validated by the expert team. The speed of the 60 meter run aims to get a score by measuring the speed of a short distance run as fast as possible with a distance of 60 meters on the students Faculty of Sport Sciences Makassar State University. Agility Aspects are measured in agility using a stopwatch to measure the time to score. Testee performs agility movements with distance of 18 meters, testee given the opportunity as much as 2 times, the result or the best score is taken which is the research data. Score is measured in seconds. In this study the agility test aims to determine one's agility. Eye-foot Coordination The score taken is 30 seconds long and is added by the number of balls that go to the target. The testee is given three times the execution, and the highest number as the score used as the research data. Validation of this research instrument is face validity

The balance is the ability of a person to get a score or score that is done with a series of movements with a pattern that changes and with a slightly longer time, ranging from star to finish by passing a predetermined obstacle without loss of balance. The result is recorded as a success or failure in this study. The test used is a Modified Bass of Dynamic Balance test. Validation of this research instrument is face validity, that is the concept of research instrument that has been standard Motivation is a physiological and psychological impulse that affect a person to achieve a goal that is driven through behavior and as a determinant of success, the test used is a questionnaire with the aim to get a score or research results. 


\section{Statistic analysis}

Statistical analysis according to Sujana (2009: 251) is to test the research hypothesis that has been proposed. These power analysis techniques include data analysis requirements test as a prerequisite for the use of analytical techniques and hypothesis testing techniques. Test requirements data analysis includes testing the normality and test data homogeneity. Test the normality of the data using the Lilliefors formula. Data is stated normal if the price of L0 $<\mathrm{Lt}$ at significant level 0,01 . The data homogeneity test is intended to test the equality of two normally distributed population variances. Test the linearity of the data and regression meanings intended to siding whether the regression obtained is really linear and has a meaning when used to make conclusions about the influence between several variables analyzed. Test linearity using ANAVA table. Linear regression is very meaningful if the price of $\mathrm{F}$ arithmetic $<\mathrm{F}$ table at the level of $\alpha=0.05$.

\section{RESULT}

Description of the Skill Result of Football Playing Data

\begin{tabular}{|c|c|c|c|c|c|c|}
\hline \multirow{2}{*}{ Statistics } & \multicolumn{6}{|c|}{ Variabel } \\
\hline & $\mathbf{X}_{1}$ & $\mathbf{X}_{2}$ & $\mathbf{X}_{3}$ & $\mathbf{X}_{4}$ & $X_{5}$ & $Y$ \\
\hline $\mathrm{N}$ & 54 & 54 & 54 & 54 & 54 & 54 \\
\hline Mean & 49,98 & 50,00 & 49,98 & 49,94 & 49,93 & 49,94 \\
\hline Median & 48,00 & 47,00 & 49,00 & 53,00 & 51,00 & 49,50 \\
\hline Std. Deviation & 9,963 & 10,030 & 10,123 & 9,995 & 10,058 & 10,038 \\
\hline Range & 43 & 37 & 37 & 37 & 32 & 42 \\
\hline Minimum & 27 & 33 & 31 & 25 & 30 & 29 \\
\hline Maximum & 70 & 70 & 68 & 62 & 62 & 71 \\
\hline Sum & 2699 & 2700 & 2699 & 2697 & 2696 & 2697 \\
\hline
\end{tabular}

Variable Skill of Playing Football (Y) Based on the data obtained in the field then analyzed statistically into the frequency distribution. So the result of research about data skill of playing football which consist of 54 samples got the highest score equal to 71 and lowest score equal to 29 , the value of the range obtained 42 while the total value obtained by 2697 . While the average value of 49.94 and standard deviation of 10,038, with the number of class intervals $=6$ while for the median score of 49.50 and the frequency distribution value of soccer playing skills can be illustrated in Table 4.1. Distribution frequency, while for the full results can be seen on the results of research data attached

Variable Speed (X1) Based on the data obtained in the field then processed statically into the frequency distribution. Then the results of research on the data speed (X1) students Faculty of Sport Science State University of Makassar which consists of 54 samples obtained the highest score of 70 and the lowest score of 27 and the value of the range obtained 43 with a total value of 2699 obtained While the average value of 49,98 and standard deviation of 9.963 , the number with the number of class intervals $=6$ while for the median number of 48.00 and the data of this speed distribution can be described in table 4.3 frequency distribution, so that for the complete results data can be seen in the data analysis results attached.

Variable agility (X2) From the data obtained in the field and then processed statistically into the frequency distribution. The result of this research is data of agility (X2) of Faculty of Sport Science State University of Makassar consist of 54 samples obtained score or highest score of 70 and lowest score 33 obtained by value of range 37 with total score 2700 while for average score 50.00 and standard deviation of 10,030 with number of class interval $=6$ whereas for median value or score equal to 47,00 and frequency distribution of eye-foot coordination can be described in table 4.4 frequency distribution, whereas for the complete result can be seen in appendix of data analysis result. 
Variable eye-foot coordination (X3) Based on the data obtained in the field, then processed statistically into the frequency distribution. The results of this study presents data of eye-foot coordination (X3) students of Faculty of Sport Science State University of Makassar consisting of 54 samples obtained the highest value of 68.31 and the lowest score obtained by 31 and the range value of 37 with a total value of 2699 while the average value average of 49.98 and standard deviation of 10.123, with the number of class intervals $=6$ while for the median sum of 49.00 and the value of the eye-foot coordination frequency distribution (X3) can be illustrated in table 4.5. in the frequency distribution, while for the full results can be seen on the results of data analysis attached. Variable balance (X4) Based on the data we get in the field then processed statistically into the frequency distribution. Result of research on data of student agility of Faculty of Sport Science State University of Makassar consist of 54 samples obtained highest score 62 and lowest score 25, obtained value range 37 with total value 2697 while for mean value $=49,94$ and standard deviation 9,995, number of interval class $=6$, while for the median score $=53.00$ and the frequency distribution of this agility can be described in table 4.6 frequency distribution, while for the complete results can be seen in the data analysis of the attachment.

Motivation variable (X5) Data obtained in the field then processed statistically into the frequency distribution. The results of the research for the motivation data consist of 54 samples obtained the highest score 62 and the lowest score obtained 30, with the value range 32 obtained the total value of 2696 while for the average value $=49.93$ and standard deviation 10.058, the number of class interval $=6$ while for the amount median score $=49.50$ with frequency distribution of motivation can be described in table 4.7 frequency distribution, while for the complete result can be seen in result of data analysis of attachment.

\section{Data Analysis Requirements Testing}

\section{Summarizing test results normality of population distribution of research data}

\begin{tabular}{|l|l|l|l|l|l|}
\hline No & Variabel & N & K-SZ $_{\text {count }}$ & Sig. (p) & Conclusion \\
\hline 1 & Speed (X1) & 54 & 0,122 & 0,044 & Normal \\
2 & Agility (X2) & 54 & 0,137 & 0,013 & Normal \\
3 & Eye-foot coordination (X3) & 54 & 0,150 & 0,004 & Normal \\
4 & Balance (X4) & 54 & 0,157 & 0,002 & Normal \\
5 & Motivation (X5) & 54 & 0,175 & 0,000 & Normal \\
6 & Soccer playing skills (Y) & 54 & 0,078 & $0,200^{*}$ & Normal \\
\hline
\end{tabular}

*. This is a lower bound of the true significance.

\section{a. Lilliefors Significance Correction}

Obtained from the calculation of the test of the normality of playing football of the students of Faculty of Sport Sciences State University of Makassar (Y) with 54 samples on the level of real $\alpha=$ $0.05(5 \%)$, the value of KS-Z count of 0.078 with a significant level (p) (K-SZcount $>\alpha=0.05$ ), so $\mathrm{H} 0$ is accepted and $\mathrm{H} 1$ is rejected. Thus it can be argued that the skills of playing football come from a population that has a normal distribution.

The result of calculation of normality velocity of student of Faculty of Sport Science State University of Makassar (X1) with sample number 54 at the level of real $\alpha=0,05$ (5\%), obtained KS-Z count value equal to 0,122 with significant level (p) 0,044 (K-S count $>\alpha=0.05$ ), so H0 is accepted and reject $\mathrm{H} 1$. Thus it can be suggested that the velocity comes from a normally distributed population.

Result of calculation of normality agility test of Faculty of Sport Sciences State University of Makassar (X2) with sample number 54 at the level of real $\alpha=0,05$ (5\%), obtained value of KS-Z count equal to 0,137 with significant level (p) 0,013 (K-S count $>\alpha=0.05$ ), so H0 is accepted and 
reject H1. Thus it can be argued that agility comes from a normally distributed population. The result of calculation of normality of eye-foot coordination of faculty student of Faculty of Sport Science State University of Makassar (X3) with sample number 54 at the level of real $\alpha=0,05(5 \%)$, obtained KS-Z count value equal to 0,150 with significant level (p) 0,004 (K-S count $>\alpha=0.05$ ), so $\mathrm{H} 0$ is accepted and reject $\mathrm{H} 1$. Thus it can be argued that eye-foot coordination comes from a normally distributed population.

The result of calculation of normality equality test of Faculty of Sport Sciences State University of Makassar (X4) with sample number 54 at the level of real $\alpha=0,05$ (5\%), obtained KS-Z count value equal to 0,157 with significant level (p) 0,002 (K-SZ count $>\alpha=0.05$ ), so H0 is accepted and reject $\mathrm{H} 1$. Thus it can be argued that the balance comes from a normally distributed population. The result of calculation of normality test of motivation of students of Faculty of Sport Science State University of Makassar (X5) with sample number 54 at the level of real $\alpha=0,05$ (5\%), obtained KS-Z count value equal to 0,175 with significant level (p) 0,000 (K-S count $>\alpha=0.05$ ), so H0 is accepted and reject $\mathrm{H} 1$. Thus it can be argued that motivation comes from a population that has a normal distribution.

\section{Homogeneity Test}

The results of the homogeneity test variance test the effect of speed, agility and eye-foot coordination, Balance and Motivation to the skills of playing football.

Test of Homogeneity of Variances

\begin{tabular}{|l|l|l|l|l|l|}
\hline No. & Hipotesis & $\begin{array}{l}\text { Levene } \\
\text { Statistic }\end{array}$ & df1 & df2 & Sig. \\
\hline 1 & $\left(\mathrm{X}_{1}\right)$ to $(\mathrm{Y})$ &, 001 & 1 & 106 &, 973 \\
\hline 2 & $\left(\mathrm{X}_{2}\right)$ to $(\mathrm{Y})$ &, 123 & 1 & 106 &, 727 \\
\hline 3 & $\left(\mathrm{X}_{3}\right)$ to $(\mathrm{Y})$ &, 019 & 1 & 106 &, 890 \\
\hline 4 & $\left(\mathrm{X}_{4}\right)$ to $(\mathrm{Y})$ &, 028 & 1 & 106 &, 868 \\
\hline 5 & $\left(\mathrm{X}_{5}\right)$ to $(\mathrm{Y})$ &, 029 & 1 & 106 &, 864 \\
\hline 6 & $\left(\mathrm{X}_{1}\right)$ to $\left(\mathrm{X}_{5}\right)$ &, 019 & 1 & 106 &, 889 \\
\hline 7 & $\left(\mathrm{X}_{2}\right)$ to $\left(\mathrm{X}_{5}\right)$ &, 032 & 1 & 106 &, 859 \\
\hline 8 & $\left(\mathrm{X}_{3}\right)$ to $\left(\mathrm{X}_{5}\right)$ &, 001 & 1 & 106 &, 975 \\
\hline 9 & $\left(\mathrm{X}_{4}\right)$ to $\left(\mathrm{X}_{5}\right)$ &, 114 & 1 & 106 &, 736 \\
\hline 10 & $\left(\mathrm{X}_{1}\right)$ to $\left(\mathrm{X}_{2}\right)$ &, 103 & 1 & 106 &, 749 \\
\hline 11 & $\left(\mathrm{X}_{1}\right)$ to $\left(\mathrm{X}_{3}\right)$ &, 011 & 1 & 106 &, 916 \\
\hline 12 & $\left(\mathrm{X}_{1}\right)$ to $\left(\mathrm{X}_{4}\right)$ &, 041 & 1 & 106 &, 840 \\
\hline 13 & $\left(\mathrm{X}_{2}\right)$ to $\left(\mathrm{X}_{3}\right)$ &, 043 & 1 & 106 &, 836 \\
\hline 14 & $\left(\mathrm{X}_{2}\right)$ to $\left(\mathrm{X}_{4}\right)$ &, 269 & 1 & 106 &, 605 \\
\hline 15 & $\left(\mathrm{X}_{3}\right)$ to $\left(\mathrm{X}_{4}\right)$ &, 092 & 1 & 106 &, 763 \\
\hline 16 & $\left(\mathrm{X}_{1}\right)$ to $(\mathrm{Y})$ through $\left(\mathrm{X}_{5}\right)$ &, 017 & 2 & 159 &, 984 \\
\hline 17 & $\left(\mathrm{X}_{2}\right)$ to $(\mathrm{Y})$ through $\left(\mathrm{X}_{5}\right)$ &, 061 & 2 & 159 &, 941 \\
\hline 18 & $\left(\mathrm{X}_{3}\right)$ to $(\mathrm{Y})$ through $\left(\mathrm{X}_{5}\right)$ &, 017 & 2 & 159 &, 984 \\
\hline 19 & $\left(\mathrm{X}_{4}\right)$ to $(\mathrm{Y})$ through $\left(\mathrm{X}_{5}\right)$ &, 057 & 2 & 159 &, 945 \\
\hline
\end{tabular}


Based on Table 4.9 it is known that the ANAVA test of playing football skills of Faculty of Sport Science students at Makassar State University is homogeneous. Explanations from each group can be described as follows:

Homogeneity test X1 to Y. According to the results of homogeneity test of variance velocity to the skills of playing soccer students Faculty of Sport Sciences State University of Makassar obtained significance value of 0.973 . Because the value of significance is greater than 0.05 . So it can be concluded that the variance of group $\mathrm{X} 1$ to $\mathrm{Y}$ is homogeneous.

Homogeneity test X2 to Y. Based on the calculation of homogeneity test of variance agility to the skills of playing football students Faculty of Sport Science State University of Makassar obtained significance value of 0.727 . Because the obtained value of significant greater than 0.05 . So it can be concluded that the variance of group $\mathrm{X} 2$ to $\mathrm{Y}$ is homogeneous.

Test homogeneity X3 to Y. According to the results of homogeneity test calculations on the variance of eye-foot coordination of the skills of playing football students Faculty of Sport Science State University of Makassar then obtained significance of 0.890 . Because the significance value obtained is greater than 0.05 , it can be concluded that the variance of group $\mathrm{X} 3$ to $\mathrm{Y}$ is homogeneous. Homogeneity test X4 to Y. According to the calculation result of homogeneity test of variance balance to the playing skill of soccer student of Faculty of Sport Science State University of Makassar obtained significant result with value equal to 0,868 . Because the significance value is greater than 0.05 so it can be concluded that the variance of group $\mathrm{X} 4$ to $\mathrm{Y}$ is homogeneous.

Test homogeneity X5 to Y. Based on the results of the homogeneity test calculation of the motivation variance of the skills of playing football students Faculty of Sport Sciences State University of Makassar then obtained a significance value of 0.864. Because the value obtained is a significance value greater than 0.05 . So it can be concluded that the variance of group $\mathrm{X} 5$ to $\mathrm{Y}$ is homogeneous.

Test homogeneity X1 to X5. Based on the results of the calculation of homogeneity test of speed variation on student motivation Faculty of Sport Science State University of Makassar obtained significance value of 0.889 . Because the significance value is greater than 0.05 it can be concluded that the variance of group $\mathrm{X} 1$ to $\mathrm{X} 5$ is homogeneous.

Test homogeneity X2 to X5. Based on the results of homogeneity test of variance agility on student motivation Faculty of Sport Science State University of Makassar obtained significance value of 0.859 . Because the value of significance is greater than 0.05 . So it can be concluded that the variance of group $\mathrm{X} 2$ to $\mathrm{X} 5$ is homogeneous.

Test homogeneity X3 to X5. In accordance with the results of homogeneity test of variance of eye-foot coordination on student motivation Faculty of Sport Science State University of Makassar obtained significance value of 0.975 . Because the value of significance obtained is greater than 0.05 so it can be concluded that the variance of group X3 to X5 is homogeneous.

Test homogeneity X4 to X5. Based on the results of the calculation of homogeneity test of variance balance to the motivation of students Faculty of Sport Science State University of Makassar got significance value of 0.736 . Due to the significance value greater than 0.05 obtained, it can be concluded that the variance of group X4 to X5 is homogeneous.

Homogeneity test X1 to X2. Based on the results of homogeneity test of velocity variation on student agility Faculty of Sport Science State University of Makassar obtained significance value of 0.749 . Because the value of significance is greater than 0.05 . So it can be concluded that the variance of group $\mathrm{X} 1$ to $\mathrm{X} 2$ is homogeneous.

Test homogeneity $\mathrm{X} 1$ to $\mathrm{X} 3$. Based on the calculation of homogeneity test of velocity variation on eye-foot coordination of Faculty of Sport Science students of State University of Makassar obtained significance value of 0.916 . Because the value of significance is greater than 0.05 . So it can be concluded that the variance of group $\mathrm{X} 1$ to $\mathrm{X} 3$ is homogeneous. 
Test homogeneity X1 to X4. Based on the calculation on the homogeneity test of variance of the variance of the balance of students Faculty of Sport Science State University of Makassar obtained significance value of 0.840 . Because the value of significance obtained is greater than 0.05 it can be concluded that the variance of group X1 to X4 is homogeneous.

Homogeneity test $\mathrm{X} 2$ to $\mathrm{X} 3$. Based on the results of homogeneity variance test of agility variance to eye-foot coordination of students of Faculty of Sport Science, State University of Makassar obtained significance value of 0.836 . Because the value of significance is greater than 0.05 . So it can be concluded that the variance of group X2 to X3 is homogeneous.

Test homogeneity X2 to X4. Based on the results of homogeneity variance test of agility variance to the balance of students Faculty of Sport Science State University of Makassar obtained significance value of 0.605 . Since the significance value obtained is greater than 0.05 it can be concluded that the variance of group X2 to X4 is homogeneous.

Test homogeneity X3 to X4. Based on the calculation of homogeneity test of variance on eyefoot coordination on the balance variance of the students of Faculty of Sport Science, State University of Makassar, there was a significance value of 0.763 . The existence of such significance value is greater than 0,05 so it can be concluded that group X3 to X4 is homogeneous.

Test homogeneity X1 to Y through X5. Based on the calculation on the homogeneity test for speed variance to the skill of playing football through student motivation Faculty of Sport Science State University of Makassar obtained significance value equal to 0,984. Because the value of significance is greater than 0.05 . it can be concluded that the variance of group X1 to $\mathrm{Y}$ through $\mathrm{X} 5$ is homogeneous.

Test homogeneity X2 to Y through X5. Based on the results of homogeneity variance test calculation of agility to the skills of playing football through the motivation of students Faculty of Sport Science State University of Makassar obtained significance value of 0.941 . The significance value greater than 0.05 obtained, it can be concluded that the variance of group X2 to Y through X5 is homogeneous.

Test homogeneity for X3 to Y through X5. Be aware of the calculation result of homogeneity test of variance of eye-foot coordination on soccer playing skill through student motivation Faculty of Sport Science State University of Makassar obtained significance value that is equal to 0,984 . Since the significance value is greater than 0.05 it can be concluded that the variance for group $\mathrm{X} 3$ to $\mathrm{Y}$ through $\mathrm{X} 5$ is homogeneous.

Test homogeneity for X4 to Y through X5. Based on the calculation on the homogeneity test of variance balance to the skills of playing football through the motivation of the students Faculty of Sport Science State University of Makassar got the significance value of 0.945 . Since the significance value is greater than 0.05 it can be concluded that the variance of group X4 to Y through X5 is homogeny.

\section{DISCUSSION}

The results of this first hypothesis show that the skills of playing football (Y) and speed (X1) produce the model of the expectation that the coefficient of double correlation $(\mathrm{R})$ obtained value of 0.612 after consultation with $r_{-}$table on degrees or $n-154-1=53$ with $\alpha=0.05$ of 0.266 then the variable $\mathrm{X} 1$ to $\mathrm{Y}$ has a significant positive correlation.

$\mathrm{R}$ Square (coefficient of determination) obtained a value of 0.374 , which means $37.4 \%$ of the overall variation of football playing skills (Y) caused by multiple regression relationship with variable speed (X1). This means that $37.4 \%$ of the velocity data (X1) gives a direct influence on the skills of playing football $(\mathrm{Y})$ and the rest of $62.6 \%$ or $(100 \%-37.4 \%=62.6 \%)$ is caused by other factors which is not included in this study.

Based on the termination coefficient, also obtained the determination value of 0.374 . This means that variations in Soccer Playing Skills can be explained by the speed variations of $37.4 \%$. The 
findings in this study are in line with the theoretical studies put forward that a good speed will be able to show good achievement as well. The level of a person's speed capability is determined by several factors according to Bompa described by Sukadiyanto and Muluk (2011: 199) factors influencing velocity, among others, determined by heredity, reaction time, strength (ability to overcome ballast load), technique, muscle elasticity, concentration and will. Meanwhile, according to Jonath / Krempel described by Syafruddin (2011: 133-135) the ability of speed is limited by factors such as muscle strength, muscle viscosity, reaction speed, contraction velocity, coordination and anthropometric characteristics. Thus it can be said that Football Playing Skills can increase when paying attention to the speed to improve Soccer Playing Skills. This is explained by

The results of the second hypothesis that the Football Playing Skills (Y) and agility (X2) produced the alleged model, that the double correlation coefficient $(\mathrm{R})$ obtained a value of 0.687 after consultation with $r$ - table on degrees of freedom (n-1) $54-1=53$ with $\alpha=0.05$ of 0.266 then the variable $\mathrm{X} 3$ to $\mathrm{Y}$ has a significant positive correlation.

R Square (coefficient of determination) obtained a value of 0.471 , which means $47.1 \%$ of the overall variation of soccer playing skills (Y) caused by multiple agility variable regression (X2). This means that $47.1 \%$ of data agility (X2) gives a direct influence on the skills of playing football (Y) and the rest of $52.9 \%$ or $(100 \%-47.1 \%=52.9 \%)$ caused by other factors which is not included in this study.

The findings in this study are in line with the theoretical studies put forward that good agility will support good performance. This is in line with the opinion of Anderson and Susan (2009: 40) states that "Agility is the ability to change directions rapidly when moving at a high rate of speed. Balance is the body's coordinated neuromuscular response to maintain the visual, tactile, or kinesthetic stimuli. "Thus it can be argued that the skills in football games can be improved when supported with good agility. The level of simple correlation coefficient between agility with the skills of playing football caused by the control of independent variables, either individually orally together. This suggests a link between agility variable and speed with agility

The result of the research for the third hypothesis states that the skills of playing football (Y) through the eye-foot coordination (X3) yielded the alleged model that the multiple correlation coefficient $(\mathrm{R})$ obtained value of 0.862 after consultation with the value of $\mathrm{r}_{-}$table on degrees of freedom (n-1) $1=53$ with $\alpha=0.05$ of 0.266 then the variable X2 to $\mathrm{Y}$ has a significant positive correlation.

R Square (coefficient of determination) obtained value of 0.743 , which means $74.3 \%$ of the overall variation of skill playing football $(\mathrm{Y})$ caused by multiple regression relationship on eye-foot coordination variables (X3). This means that $74.3 \%$ of eye-foot coordination data (X3) gives a direct influence on the skills of playing football $(\mathrm{Y})$ and the rest of $25.7 \%$ or $(100 \%-74.3 \%=25.7 \%)$ is caused by factors - other factors not included in this study.

The findings in this study are in accordance with the theoretical studies put forward that the effect of good eye-foot coordination will be able to show good footballing skills as well. According to Harsono (2015: 39) states, "speed, strength, endurance, formation, kinesthetic, sense, balance, and rhythm all contribute to and combine in motion coordination, therefore each other has a close relationship". Thus it can be said that the skills of playing football can be increased incase of increased eye-foot coordination so that the skills of playing football will be higher. The result of the research on the fourth hypothesis which states that Football Playing Skill (Y) through equilibrium (X4) produces an alleged model, that the double correlation coefficient $(\mathrm{R})$ is obtained value of 0.636 after consultation with $r_{-}$table on degrees of freedom (n-1) $54-1=53$ with $\alpha$ $=0.05$ of 0.266 then the variable $\mathrm{X} 4$ to $\mathrm{Y}$ has a significant positive correlation. $\mathrm{R}$ Square (coefficient of determination) obtained value 0.404 which means $40.4 \%$ of the overall variation of football playing skills $(\mathrm{Y})$ caused by multiple regression relationships for the balance variable (X4). This means that $40.4 \%$ of equilibrium data (X4) gives a direct influence on the skills of 
playing football $(\mathrm{Y})$ and the rest of $59.6 \%$ or $(100 \%-40.4 \%=59.6 \%)$ caused by other factors which is not included in this study.

The findings in this study are in line with the theoretical studies put forward that the effect of a good balance will be able to show good footballing skills as well. According to Torbert (2011: 13) states that: "In at least three periods of life, people may need to learn or redevelop some aspects of this physical skill-toddlerhood, adolescence (when the body may be in a rapid state of change) and as a senior citizen. "Thus it may be argued that that the skills of playing football can increase as the balance increases so that the skills of playing football will increase.

The result of the fifth hypothesis study which states that the skills of playing football (Y) through motivation (X5) yielded the alleged model that the double coefficient (R) obtained value of 0.816 after consultation with $\mathrm{r}_{-}$table on degrees of freedom (n-1) $50-1=59$ with $\alpha=0.05$ of 0.266 then the variable $\mathrm{X} 5$ to $\mathrm{Y}$ has a significant positive correlation.

R Square (coefficient of determination) obtained a value of 0.666 , which means $66.6 \%$ of the overall variation of soccer playing skills $(\mathrm{Y})$ is caused by multiple regression relationship with motivation variable (X5). This means that $66.6 \%$ of motivational data (X5) gives a direct influence on the skills of playing football $(\mathrm{Y})$ and the balance of $33.4 \%$ or $(100 \%-66.6 \%=33.4 \%)$ is caused by other factors which is not included in this study.

The findings of this study are in line with the theoretical studies put forward that the influence of good motivation that is able to show good football skills as well. Further according to Christine. Wegner, Jordan and Daniel (2015: 372) states that: "Motivation is a psychological state that directs or activates behaviors, which can be categorized into intrinsic and extrinsic motivation," Intrinsic motivation "refers to doing an activity for the inherent satisfaction of the activity "Thus it can be said that Soccer Playing Skills can increase as motivation increases so the skills of playing football will be higher.

The result of the research on the sixth hypothesis which states that the velocity (X1) through motivation (X5) produces the alleged model, that the double correlation coefficient (R) is obtained value of 0,531 after consultation with $r_{-}$table on degrees of freedom (n-1) $54-1=53$ with $\alpha=0.05$ of 0.266 then the variable $\mathrm{X} 1$ to $\mathrm{X} 5$ has a significant positive correlation.

$\mathrm{R}$ Square (coefficient of determination) obtained value of 0.282 , which means $28.2 \%$ of the total variation of motivation (X5) caused by variable variance regression variable speed (X1). This means that 28.2\% speed data (X1) gives a direct influence on the motivation of students of Faculty of Sport Science State University of Makassar (X5) and the rest equal to $71.8 \%$ or $(100 \%-28.2 \%=$ $71.8 \%$ ) caused by other factors not included in this study.

Based on the correlation coefficient, will be obtained coefficient of determination of 0.282 so that the findings in this study indicate the importance of speed variables to improve student motivation Faculty of Sport Science State University of Makassar, because it can explain the variation of Playing Skills football by $28.2 \%$. This is in line with the theory put forward by Dlis (2015: 16) Motivation derived from the Latin "movere" which means to move for example mentions that motivation represents the psychological processes that cause the emergence, directed, and the persistence of volunteer activities which is directed toward a particular destination. The result of the research on the seventh hypothesis which states that agility (X2) through motivation (X5) produces the alleged model that the double correlation coefficient $(\mathrm{R})$ obtained value of 0.702 after consultation with $r_{-}$table on degrees of freedom ie (n-1) $54-1=53$ with $\alpha=0.05$ of 0.266 then the variable $\mathrm{X} 2$ to $\mathrm{X} 5$ has a significant positive correlation.

R Square (coefficient of determination) obtained a value of 0.386 , which means $38.6 \%$ of the total variation of motivation (X5) caused by multiple regression relationship agility variable that is (X2). This means that $38.6 \%$ of data agility (X2) gives a direct influence on the motivation of students of Faculty of Sport Science State University of Makassar (X5) and the rest is $61.4 \%$ or $(100 \%-38.6 \%$ $=61.4 \%$ ) caused by other factors not included in this study. 
Based on the correlation coefficient, will be obtained coefficient of determination of 0.386 so that the findings in this study indicate the importance of agility variables to improve student motivation Faculty of Sport Science State University of Makassar because it can explain the variation of soccer playing skills by $38.6 \%$. This is in line with the theory described by Mc. Donald in Oemar Hamalik (2012: 173)explains that "Motivation is the change of energy in a person's person characterized by the emergence of afaktif and reaction to achieve the goal.

The result of the research on the eighth hypothesis which states that the eye-foot coordination (X3) through motivation (X5) produces the alleged model, that the double correlation coefficient (R) is obtained by 0.743 after consultation with $r_{-}$tabel on degrees of freedom (n-1) $54-1=53$ with $\alpha=$ 0.05 of 0.266 then the variable X3 to X5 has a significant positive correlation.

$\mathrm{R}$ Square (coefficient of determination) obtained a value of 0.551 , which means $55.1 \%$ of the total variation of motivation (X5) caused by multiple regression relationships variables eye-foot coordination (X3). This means that $55.1 \%$ of eye-foot coordination data (X3) gives a direct influence on the motivation of students of Faculty of Sport Science State University of Makassar (X5) and the rest of $44.9 \%$ or $(100 \%-55.1 \%=44.9 \%)$ caused by other factors not included in this study.

Based on the correlation coefficient will be obtained coefficient of determination of 0.551 . Thus, the findings in this study indicate the importance of eye-foot coordination variables in improving student motivation Faculty of Sport Science, Makassar State University. Because it can explain the variation of soccer playing skills by $55.1 \%$. This is in line with the theory put forward by Harsono (2015: 158) states "a skill or skill requires coordination. Required coordination in skills such as foot-eye coordination and eye-hand coordination. Foot-eye coordination is required in movements such as in the kicking of the ball skills, accompanying the ball ".

The result of the research on the ninth hypothesis which states that the equilibrium (X4) through motivation (X5) yields the alleged model, that the double correlation coefficient (R) is obtained by 0.564 after consultation with r_table on degrees of freedom (n-1) $54-1=53$ with $\alpha=$ 0.05 of 0.266 then the variable $\mathrm{X} 4$ to $\mathrm{X} 5$ has a significant positive correlation.

R Square (coefficient of determination) obtained a value of 0.318 , which means $31.8 \%$ of the total variation of motivation (X5) caused by the relationship of multiple regression of balance variable (X4). This means that $31.8 \%$ of equilibrium data (X4) gives a direct influence on the motivation of students of Faculty of Sport Science State University of Makassar (X5) and the rest of $68.2 \%$ or $(100 \%-31.8 \%=68.2 \%)$ caused by other factors not included in this study.

The results of this hypothesis analysis provide findings that balance contributes to motivation. These findings mean that if you want to increase motivation it can be done with increased equilibrium. This is in line with the opinion Widiastuti (2011: 7-8) is Achievement score / results in sports that can be a child's war. This is an objective assessment that can be used to determine the level of child's skills at the time and not on the subjective nature of the teacher. As we understand that every child is happy to know his status at that time, and he can stimulate himself to practice diligently The results of this tenth hypothesis show that the skills of playing football (Y) and velocity (X1) through motivation (X5) resulted in the alleged model that the double correlation coefficient (R) obtained value of 0.817 after consultation with r_tabel on degrees or degrees of freedom (n- 1) 54 - 1 $=53$ with $\alpha=0.05$ of 0.266 then the variable $\mathrm{X} 1$ to $\mathrm{Y}$ through $\mathrm{X} 5$ has a significant positive correlation.

R Square (coefficient of determination) obtained a value of 0.668 , which means $66.8 \%$ of the overall variation in the skills of playing football (Y) due to the multiple regression relationship with variable speed (X1) to the skills of playing football (Y) through motivation (X5). This means that $66.8 \%$ of the speed data (X1) gives a direct influence on the skills of playing football (Y) through motivation (X5) and the rest of $33.2 \%$ or $(100 \%-66.8 \%=33.2 \%)$ caused by other factors not included in this study. 
The findings in this study are in line with the theoretical studies put forward that good speed and high motivation will be able to show good achievement as well. Winardi (2007: 6) Motivation is a potential force within a human being, which can be self-explored or developed by a number of outside forces that essentially revolve around monetary and nonmonetary rewards, which can affect their work positively or negatively, which depends on the situation and conditions faced by the person concerned. Thus it can be said that the skills of playing football can increase when paying attention to the speed and motivation to improve the skills of playing football

The result of this twelfth hypothesis study shows that the skills of playing football (Y) and eye-foot coordination (X3) through motivation (X5) resulted in the alleged model that the double correlation coefficient $(\mathrm{R})$ obtained value of 0.820 after consultation with $\mathrm{r}_{-}$tabel on degrees or degrees of freedom (n-1) $54-1=53$ with $\alpha=0.05$ of 0.266 then the variable X3 to Y through X5 has a significantly positive correlation.

R Square (coefficient of determination) obtained a value of 0.672 , which means $67.2 \%$ of the overall variation of football playing skills $(\mathrm{Y})$ due to multiple regression relationship with eye-foot coordination variables (X3) on the skills of playing football (Y) through motivation (X5). This means that $67.2 \%$ eye-foot coordination data (X3) gives a direct influence on the skills of playing football (Y) through motivation (X5) and the rest of $32.8 \%$ or $(100 \%-67.2 \%=32.8 \%)$ is caused by other factors not included in this study.

Based on the termination coefficient, also obtained the determination value of 0.672 . This means that variations in Soccer Playing Skills can be explained by variations in eye-foot coordination and motivation by $67.2 \%$. The findings in this study are in line with the theoretical studies put forward that good coordination and high motivation will be able to show a good achievement as well. Described by According to Hanafiah and Suhana (2012: 26) motivation to learn is a power (power motivation), the driving force (diving force), or a tool for the development of willingness and strong desire in learners to learn actively, creative, effective, innovative and fun in behavioral changes, both in the cognitive, affective and psychomotor aspects. Thus it can be said that the playing skills of football can be improved when paying attention to eye-foot coordination and motivation to improve the skills of playing football.

The result of this thirteen hypothesis shows that the skills of playing football (Y) and equilibrium (X4) through motivation (X5) resulted in the alleged model that the double correlation coefficient (R) was obtained by 0.818 after consultation with $r_{-}$table on degrees or $\left.n-1\right) 54-1=53$ with $\alpha=0.05$ of 0.266 then the variable $\mathrm{X} 4$ to $\mathrm{Y}$ through $\mathrm{X} 5$ has a significant positive correlation. R Square (coefficient of determination) obtained a value of 0.670 , which means $67.0 \%$ of the overall variation of soccer playing skills $(\mathrm{Y})$ due to the relationship of multiple regression with the balance variable (X4) to the skills of playing football (Y) through motivation (X5). This means that $67.0 \%$ of the balance data $(\mathrm{X} 4)$ gives a direct influence on the skills of playing football (Y) through motivation (X5) and the remaining $33 \%$ or $(100 \%-67.0 \%=33 \%)$ is caused by factors others not included in this study.

Based on the termination coefficient, also obtained the determination value of 0.670 . This means that variations in Soccer Playing Skills can be explained by the variation of balance and motivation by $67.0 \%$. The findings in this study are in line with the theoretical studies put forward that a good balance and high motivation will be able to show a good achievement achievement as well. This is said by Djaali (2008: 101) suggests motivation is the physiological and psychological conditions contained in a person who encourages him to perform certain activities in order to achieve a goal (needs) Thus it can be said that the skills of playing football can increase when considering the balance and motivation to improve the skills of playing football.

Based on the results of hypothesis testing together or individually turned out the speed, agility, eye-foot coordination, balance and motivation have a significant effect on the skills of playing football. The structural equation of path analysis results from variable speed, agility, eye-foot 
coordination, balance and motivation to soccer playing skills are as follows: $\mathrm{X} 5=0,000 \mathrm{X} 1+0,000$ $\mathrm{X} 2+0,000 \mathrm{X} 3+0,000 \mathrm{X} 4+0.371 \varepsilon 2$

The amount of contribution of speed, agility, eye-foot coordination, balance and motivation jointly to the skills of playing football is equal to $62.9 \%$ while $37.1 \%$ or $(100 \%-62.9 \%=37.1 \%)$ the rest is influence of other variables other than variable speed, agility, eye-foot coordination, balance and motivation. The other variables that can affect the motivation include internal factors that include student carrier, past experience, ideals and expectations. While that includes external factors include the facilities available, facilities and infrastructure, exercise programs and the environment. The contribution of agility variable (X1) to motivation (X5) directly is $0,5312 \times 100 \%=28,2 \%$. Variables agility (X2) has a direct contribution of $0.6212 \times 100 \%=38.6 \%$. The eye-foot coordination variable $(\mathrm{X} 3)$ has a direct contribution of $0.7432 \times 100 \%=55.1 \%$. For the balance variable $(\mathrm{X} 4)$ has a direct contribution of $0.5642 \times 100 \%=31.8 \%$. Influence between speed, agility, eye-foot coordination, balance and motivation correlated to soccer playing skills $(0,531 \times 0,621 \times 0,743 \times$ $0,564) \times 100 \%=13,818 \%$.

The total overall effect of speed either directly or indirectly to motivation is $28.2 \%+13.818 \%$ $=42.018 \%$. Total influence of agility either directly or indirectly to motivation is $38.6 \%+13.818 \%=$ $52.418 \%$. Total influence of eye-foot coordination either directly or indirectly to motivation is $55.1 \%$ $+13.818 \%=68.918 \%$. Total influence of balance either directly or indirectly to motivation is $31,8 \%$ $+13,818 \%=45,618 \%$.

These findings indicate that in improving motivation, players must have speed, agility, eye-toeye coordination and a good balance in which both contribute $62.9 \%$ which can increase motivation. Secondly, the hypothesis has a significant influence on agility, speed, eye-foot coordination, balance and motivation collectively to the skill variables in playing on the game of football after hypothesis testing are jointly significant as well as at the time of individual test is also significant .

Based on the results of hypothesis testing jointly or individually turned out variable speed, agility, eye-foot coordination, balance and motivation have a significant effect on the skills of playing football. The equation of the structure of the path analysis results from the speed, agility, eye-foot coordination, balance and motivation of soccer playing skills are as follows $\mathrm{Y}=0,000 \mathrm{X} 1+0.00 \mathrm{X} 2$ $+0,000 \mathrm{X} 3+0,000 \mathrm{X} 3+0,000 \mathrm{X} 3+0.157 \varepsilon 1$

The amount of contribution from variable speed, agility, eye-foot coordination, balance and motivation collectively to soccer skill is $84,3 \%$ while $15,7 \%$ or $(100 \%-84,3 \%=15,7 \%)$ the rest is the influence of other variables other than the variable speed, agility, eye-foot coordination, balance and motivation. Other variables that can influence the skills in playing football include the technique of herding, kicking, throwing and others effectively and efficiently as expected.

Contribution of agility variable that is (X1) to the skill variable of playing football (Y) is directly equal to $0,6122 \times 100 \%=37,4 \%$. Variables agility $(\mathrm{X} 2)$ has a direct contribution of $0.6872 \times$ $100 \%=47.1 \%$. The eye-foot coordination variable (X3) which has a direct contribution of $0.8622 \mathrm{x}$ $100 \%=74.3 \%$. The balance variable $(\mathrm{X} 4)$ has a direct contribution of $0.6362 \times 100 \%=40.4 \%$. While the motivation variable (X5) has a direct contribution of $0.8162 \times 100 \%=66.6 \%$. Influence between velocity variables, agility, eye-foot coordination, balance and correlated motivation correlated to the skills in playing football games $(0.612 \times 0.687 \times 0.862 \times 0.636 \times 0.816) \times 100 \%=18.809 \%$.

The total influence of variable speed both directly and indirectly to the skills of playing football is equal to $37.4 \%+18.809 \%=56.209 \%$. Total influence of agility, either directly or indirectly to the variables of playing football skills is $47.1 \%+18.809 \%=65.909 \%$. Total influence of eye-foot coordination variables either directly or indirectly to the skills of playing football is equal to $74.3 \%+18.809 \%=93.109 \%$. Total influence of the balance either directly or indirectly to the skills of playing football is equal to $40.4 \%+18.809 \%=59.209 \%$. And the total influence of the speed either directly or indirectly to the skills of playing football is equal to $66.6 \%+18.809 \%=85.409 \%$. 
These findings indicate that to improve the skills of playing football should have the speed, agility, eye-to-eye coordination, balance and good motivation for the five variables together have contributed $84.5 \%$ that can improve the skills of playing football.

\section{CONCLUSION}

The conclusions are based on research findings with exogenous variables consisting of velocity (X1), agility (X2), eye-foot coordination (X3), equilibrium (X4) and motivation (X5). While Endogen Variable consists of Skill Play Football (Y). There is a positive influence between the speed (X1) on the skills of playing football (Y) on the students of Faculty of Sport Science, Makassar State University. There is a positive influence between agility (X2) on the skills of playing football (Y) on the students of Faculty of Sport Science, Makassar State University. There is a positive influence between eye-foot coordination (X3) on the skills of playing football (Y) on the students of Faculty of Sport Science, Makassar State University. There is a positive influence between the balance (X4) on the skills of playing football $(\mathrm{Y})$ on the students of the Faculty of Sport Science, Makassar State University. There is a positive influence between the motivation (X5) on the skills of playing football (Y) on the students of Faculty of Sport Science, Makassar State University. There is a positive influence between the speed (X1) on the motivation (X5) on the students of Faculty of Sport Science, Makassar State University. There is a positive influence between agility (X2) on motivation (X5) on students of Faculty of Sport Science, Makassar State University.There is a positive influence between eye-foot coordination (X3) on motivation (X5) on students of Faculty of Sport Science, Makassar State University. There is a positive influence between the balance (X4) on the motivation (X5) on the students of Faculty of Sport Science, Makassar State University. There is a positive influence between the speed (X1) on the skills of playing football (Y) through motivation (X5) on the students of Faculty of Sport Science, Makassar State University. There is a positive influence between agility (X2) on the skills of playing football (Y) through motivation (X5) on the students of Faculty of Sport Science, Makassar State University.There is a positive influence between eye-foot coordination (X3) on the skills of playing football (Y) through motivation (X5) on the students of Faculty of Sport Science State University of Makassar. There is a positive influence between the balance (X4) on the skills of playing football (Y) through motivation (X5) on the students of Faculty of Sport Science, Makassar State University.

\section{REFERENCE}

Anderson and Susan. (2009). Foundations of Athletic Training: Prevention, Assessment, and Management. USA. Library of Congress Cataloging-in-Publication Data.

Antonio Garcia Juan, Menayo Ruperto And Del Val Pablo. (2017). Speed-accuracy trade-off in a 7 meter throw in handball with real constraints: Journal of Physical Education and Sport (JPES), 17 (3), Art 180, pp. 1172 - 1176.

Atmojo, M.B. (2010). Test and Measurement in Physical Education and Sport. Surakarta: UNS Press.

Calatayud Joaquin, Martín Fernando, C Juan. Colado, Benavent Juan, María C. Martinez, Flandez Jorge. (2017). Relationship between the modified star excursion balance test and the $4 \times 10 \mathrm{~m}$ shuttle run test in children, CCD, Volume 12.

Djaali. (2015). Educational Psychology. Jakarta: PT Bumi Aksara, 2008

Dlis, Word "Sociology of Sports. Malang: Wineka Media.

Hamalik. Oemar. (2012). Psychology Learning and Teaching. Bandung: Sinar Baru Algensidi.

Hanafiah, Nanang and Suhana. (2012). Grandchild, Concept of Learning Strategy. Bandung: Refika Aditama.

Harsono. (2015). Periodization of Exercise Program. Bandung: PT Remaja Rosdakarya. (2015). Sports Coaching Theory and Methodology. Bandung: PT Remaja Rosdakarya.

Husdarta. (2013). Learning and Learning Physical Education and Health. Bandung: Alfabeta.

Marianne Torbert. (2011). Secrets to success in sport \& play a practical guide to skill development. America: Human Kinetics Versa Press. 
Mathisen Dan Danielsen. (2014). Effects of speed exercises on acceleration and agility performance in 13-year-old female soccer players, Journal of Physical Education and Sport (JPES), Vol. 14 (4), ISSN: 2247 - 8051.

Sudjana. Nana. (2009). Statistics Method. Bandung: Tarsito.

Sukadiyanto and Muluk, Dangsina. (2011). Introduction to Theory and Methodology Physical Training. Bandung: Lubuk Agung.

Syafruddin. (2011). Science of Sports Coaching, Theory and Its Application in Sport Coaching. Padang: UNP Press.

Tangkudung. (2012). Sports Coaching, Sport Achievement Development, First Printing. Jakarta: Cerdas Jaya.

(2016). Kinds of Research Methodology Description and Examples. Jakarta: Lens Media Reader.

Tenang D John. (2008). Faster Playing Mahjong. Bandung: DAR Mizan.

Terry McMorris. (2007). Acquisition and Performance of Sports Skills. England: Wiley Sport Texts Series.

Widiastuti. (2011). Tests and Measurements of Sports. Jakarta: Earth Script.

----------(2015). Tests and Measurements of Sports. Jakarta: PT. Raja Grafindo Persada.

Winardi, J. (2007). Motivation In Management. Jakarta: RajaGrafindo Persada.

Yudianto. Lukman. (2009). Techniques playing football and futsal. Jakarta: Horizon.

Zago Metteo, Giuriola Massimo and Sforza Chiarella. (2016). Effects of a combined technique and agility program on youth soccer players' skills, International Journal of Sports Science \& Coaching, Vol. 11 (5). 